\title{
Produção de serapilheira em um fragmento adjacente a uma cava de mineração, Ribeirão Grande, SP
}

\author{
Leandro S. Nascimento ${ }^{1}$, Roberta M. Cerqueira ${ }^{2} \&$ Bruna L. R. Henderson ${ }^{2}$ \\ ${ }^{1}$ Faculdade de Tecnologia do Estado de São Paulo. Capão Bonito, SP. Email: leandro.sudario01@hotmail.com \\ ${ }^{2}$ Programa de Pós-Graduação em Ciências Ambientais/Centro de Ciências Naturais e Tecnologia/Universidade do Estado do Pará. Belém, PA. \\ romacedo1976@yahoo.com.br (Autora correspondente); lorenahenderson@hotmail.com
}

\section{Palavras-chave:}

monitoramento ambiental

Floresta Estacional Semidecídua Montana

funções ecossistêmicas

\section{R E S U M O}

Realizou-se este estudo com o objetivo de avaliar a produção de serapilheira em um fragmento florestal adjacente a uma cava de mineração de calcário, Ribeirão Grande (SP). O material foi coletado mensalmente entre os meses de fevereiro de 2011 a janeiro de 2012. Foram utilizados 14 coletores de madeira $(0,25 \times 0,25 \mathrm{~m})$, suspensos $20 \mathrm{~cm}$ acima da superfície do solo. Em laboratório o material interceptado nos coletores foi triado nas frações: folhas, caules, flores, frutos e sementes, ramos com até $2 \mathrm{~cm}$ de diâmetro e restos (material fecal, insetos e plântulas), secado em estufa a $70^{\circ} \mathrm{C}$ e pesado em balança analítica. A produção anual média de serapilheira para a área foi de $2809,02 \mathrm{~g} \mathrm{~m}^{-2}$. Dentre as frações da serapilheira a que mais contribuiu para a produção total foi a fração folhas representando $73,86 \%$ do peso seco total $\left(2074,74 \mathrm{~g} \mathrm{~m}^{-2}\right)$, seguida da fração ramos, com $18,89 \%$ da serapilheira total $\left(530,67 \mathrm{~g} \mathrm{~m}^{-2}\right)$, frutos e sementes 3,39\% $\left(95,18 \mathrm{~g} \mathrm{~m}^{-2}\right)$, restos $2,65 \%\left(74,48 \mathrm{~g} \mathrm{~m}^{-2}\right)$ e flores com $1,21 \%(33,95 \mathrm{~g}$ $\mathrm{m}^{-2}$ ). Pelos resultados obtidos não há evidências de que a presença da mina esteja interferindo na produção de serapilheira haja vista que os dados alcançados se assemelham aos de outros trabalhos já publicados sobre o tema.

\section{Key words:}

environmental monitoring

Montane Semideciduous Seasonal

Forests

ecosystem functions

\section{Litterfall production in a fragment adjacent to a mining pit, Ribeirão Grande, SP}

\begin{abstract}
A B S T R A C T
The study aimed at evaluating litterfall production in a forest fragment adjacent to a limestone mining pit, in Ribeirão Grande (SP - Brazil). The material was collected monthly between the months of February 2011 to January 2012. Fourteen timber collectors $(0,25$ x $0,25 \mathrm{~m}$ ) were used, suspended $20 \mathrm{~cm}$ above the soil surface. In the laboratory, the material intercepted was separated into fractions: leaves, stems, flowers, fruits and seeds, branches up to $2 \mathrm{~cm}$ in diameter and debris (fecal material, insects and seedling), dried at $70{ }^{\circ} \mathrm{C}$ and weighed on an analytical scale. The mean annual litterfall production for the 7 strips in 14 plots was estimated at $2809.02 \mathrm{~g} \mathrm{~m}^{-2}$. Among the fractions of litterfall, leaves presented as the largest contributor to total production, representing $73.86 \%$ of the total dry weight $\left(2074.74 \mathrm{~g} \mathrm{~m}^{-2}\right)$, followed by the branches fraction, with $18.89 \%$ of total litterfall $\left(530.67 \mathrm{~g} \mathrm{~m}^{-2}\right)$, fruits and seeds $3.39 \%\left(95.18 \mathrm{~g} \mathrm{~m}^{-2}\right)$ debris $2.65 \%\left(74.48 \mathrm{~g} \mathrm{~m}^{-2}\right)$ and flowers with $1,21 \%\left(33.95 \mathrm{~g} \mathrm{~m}^{-2}\right)$. There is no evidence that the presence of the mine is affecting litterfall production, since the data obtained are similar to data in other studies published on the subject.
\end{abstract}




\section{INTRODUÇÃo}

O Brasil é um dos países com maior diversidade do mundo concorrendo com a Indonésia pelo título de nação biologicamente mais rica do planeta (Mittermeier et al., 2005). O Bioma Mata Atlântica ou Domínio Atlântico, é um dos 34 hotspots mundiais, sendo uma área prioritária para conservação. Composto por um mosaico de biodiversidade, o bioma perdeu pelo menos $70 \%$ de sua cobertura vegetal original; entretanto, ainda abriga mais de $60 \%$ de todas as espécies terrestres do planeta (Leal \& Câmara, 2005).

A Mata Atlântica é, provavelmente, o ecossistema mais devastado e mais seriamente ameaçado do planeta. Seu elevado grau de fragmentação levou à formação de um grande número de remanescentes isolados e pulverizados, muitos com dimensões insuficientes para sustentar, genética e ecologicamente, as populações associadas (Câmara \& Coimbra Filho, 2000). Além da perda genética e biológica, algumas funções ecossistêmicas podem ficar ameaçadas ou serem alteradas pela fragmentação dos habitats, entre elas o retorno de nutrientes para o solo através da decomposição da serapilheira.

A serapilheira é o material presente na parte superficial do piso da floresta, constituído por folhas, caules, ramos, frutos, flores e outras partes da planta, bem como resto de animais e material fecal (Scoriza et al., 2012). A camada de serapilheira sobre o solo depende, além da produção, da velocidade de decomposição da matéria orgânica, que varia conforme a composição do substrato, da atividade dos decompositores e das condições ambientais, particularmente temperatura, umidade e propriedades físicas do solo (Spain, 1984).

Em ecossistemas florestais tropicais conservados ocorre uma produção contínua de serapilheira no decorrer do ano (Werneck et al., 2001), cuja quantidade total produzida nas diferentes épocas depende do tipo e da composição da vegetação estudada (Schumacher et al., 2011), das características bióticas e abióticas das áreas e do grau de perturbação e conectividade das áreas (Figueiredo Filho et al., 2003; Vidal et al., 2007, Machado et al., 2008). Com base nisto, o aporte de serapilheira em áreas submetidas a distúrbios pode ser empregado como indicador visando avaliar o processo de recuperação da vegetação (Martins \& Rodrigues, 1999). A estrutura vertical e a horizontal da comunidade vegetal e a composição e distribuição de espécies também podem interferir na distribuição e na produção de serapilheira (Vidal et al., 2007). Sendo assim, a serapilheira pode ser classificada como um bioindicador de reação, uma vez que responde com alterações em seus processos de deposição em função de alterações no meio (Klumpp, 2001).

Os efeitos ambientais da mineração estão associados, de modo geral, às diversas fases de exploração dos bens minerais, como a abertura da cava (retirada da vegetação, escavações, movimentação de terra e modificação da paisagem local); ao uso de explosivos no desmonte das rochas (sobre pressão atmosférica, vibração do terreno, ultra lançamento de fragmentos, fumos, gases, poeira, ruído) e ao transporte e beneficiamento do minério (geração de poeira e ruído), afetando os meios como água, solo e ar, além da população local (Bacci et al., 2006). Porém, embora muitos efeitos ambientais causados pelo processo de mineração não sejam bem conhecidos, ainda são inexpressivos os estudos sobre as influências da mineração em vegetações localizadas em áreas do entorno a cavas de mineração de calcário (CCRG, 2012).

Neste estudo se analisou, portanto, a produção de serapilheira de um Fragmento de Floresta Estacional Semidecídua (IBGE, 2012) adjacente a uma cava de mineração de calcário considerando as seguintes hipóteses: a) há uma variação nos valores de deposição de serapilheira ao longo do ano e nas estações do ano; b) acreditamos, dentre as frações coletadas, que a fração folha será a mais representativa; c) existe uma diferenciação na quantidade de serapilheira coletada conforme a proximidade ou o distanciamento da cava de mineração de calcário.

Neste contexto o propósito foi avaliar a produção anual de serapilheira em um trecho de 2 ha de Floresta Estacional Semidecídua Montana no município de Ribeirão Grande, SP, verificando a diferença de deposição entre as frações, estações do ano e distanciamentos da cava de mineração, comparando os resultados encontrados com as características estruturais, florísticas e o estado de conservação do fragmento.

\section{Material e Métodos}

A coleta dos dados foi realizada em um fragmento florestal adjacente a uma cava de mineração de metacalcário e argila, localizado no município de Ribeirão Grande/SP (24 $09^{\prime} 20^{\prime \prime} \mathrm{S}$ e $24^{\circ} 10^{\prime} 30^{\prime \prime} \mathrm{S}$ e $48^{\circ} 18^{\prime} 30^{\prime \prime} \mathrm{W}$ e $48^{\circ} 21^{\prime} 00^{\prime \prime} \mathrm{W}$ ).

O clima da região é classificado como Cfa de Köppen, sendo uma região de transição climática entre o clima tropical quente, das latitudes baixas, e o temperado mesotérmico, das latitudes médias, com influência da altitude. A temperatura média anual é inferior a $22^{\circ} \mathrm{C}$, podendo ocorrer de um a quatro eventos de geada a cada ano (Baider, 1994) A precipitação média anual é em torno de $1.720 \mathrm{~mm}$, com chuvas concentradas no verão, principalmente nos meses de dezembro a fevereiro sendo que, no inverno, a mínima pluviométrica pode chegar a $30 \mathrm{~mm}$ (CCRG, 2003).

$\mathrm{Na}$ área de estudos predomina a Floresta Estacional Semidecídua Montana (IBGE, 2012) mas, devido à proximidade com a Serra de Paranapiacaba, também ocorrem espécies típicas da Floresta Ombrófila Densa Montana (Jakovac, 2007).

Há predomínio de solos argilosos, como Litossolos Vermelho e Amarelo e Podzólicos Vermelhos-Amarelo (Baider, 1994). Em algumas áreas desta região, inclusive na área de estudo, ocorrem manchas de solos calcários que resultam em uma floresta com composição florística diferente dos arredores. Esta formação é considerada especialmente importante para a conservação da biodiversidade neotropical por ser um dos poucos locais no Brasil onde ocorre (Aidar et al., 2001). A área apresenta topografia bastante acidentada, com declives acentuados e vales bem encaixados, o que pode aumentar a heterogeneidade dos solos (Jakovac, 2007).

Devido à abertura da cava para a exploração de minérios, a vegetação arbórea do entorno ou adjacente à mineração, está sendo monitorada desde o ano de 2005, com o objetivo de avaliar a interferência deste empreendimento na estrutura 
e na florística das espécies encontradas no fragmento. Foi estabelecida uma metodologia que consistiu na definição de sete "Faixas" (de aproximadamente $2.000 \mathrm{~m}^{2}$ ) com uma largura de $20 \mathrm{~m}$ cada uma (e comprimento variável, mas em torno de $1000 \mathrm{~m}$ ), sendo que a primeira faixa se localiza próximo ao limite máximo em que a cava da mina irá atingir (10 $\mathrm{m}$ do limite da cava) e as outras seguem na direção do contínuo de vegetação com distâncias de 20, 40, 80, 160, 320 e $640 \mathrm{~m}$ da cava de mineração (Figura 1). Esta área foi, então, dividida em uma grade amostral composta de 70 parcelas de $10 \times 10 \mathrm{~m}$, ressaltando-se que em cada faixa foram plotadas 10 parcelas totalizando 70 parcelas $\left(7.000 \mathrm{~m}^{2}\right)$. A quantidade de parcelas para cada lado da trilha é variável (Figura 2) devido às limitações impostas pela topografia da área.

\section{Produção de serapilheira}

Para a coleta de dados da serapilheira seguimos as recomendações metodológicas propostas por Scoriza et al. (2012) com algumas alterações. Foram utilizados 14 coletores de madeira de $0,5 \times 0,5 \mathrm{~m}\left(0,25 \mathrm{~m}^{2}\right)$ com fundo em tela de nailon com malha de $1 \times 1 \mathrm{~mm}$, suspensos $20 \mathrm{~cm}$ acima da superfície

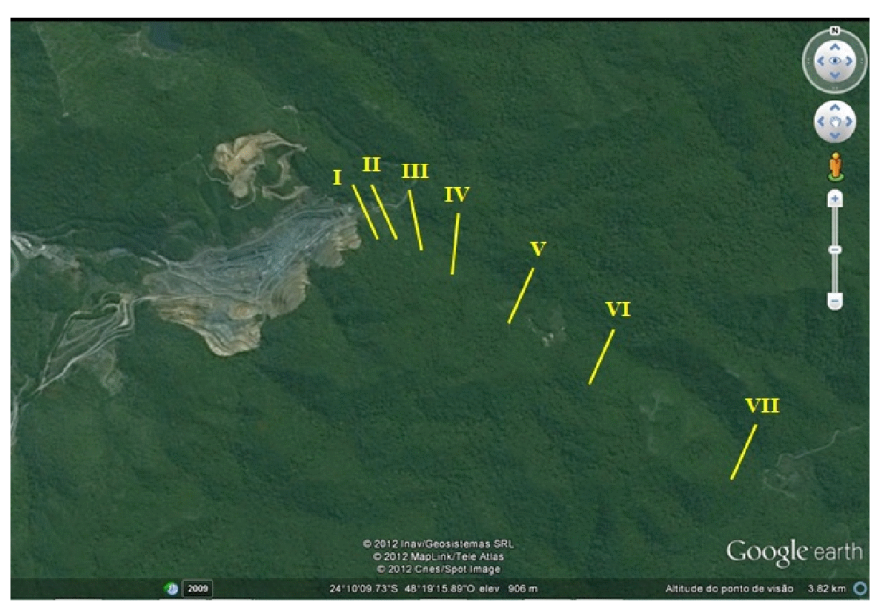

Figura 1. Área de coleta (contínuo de vegetação) com a posição das faixas (I, II, II, IV, V, VI e VII) em que estão instaladas as parcelas para acompanhamento da vegetação

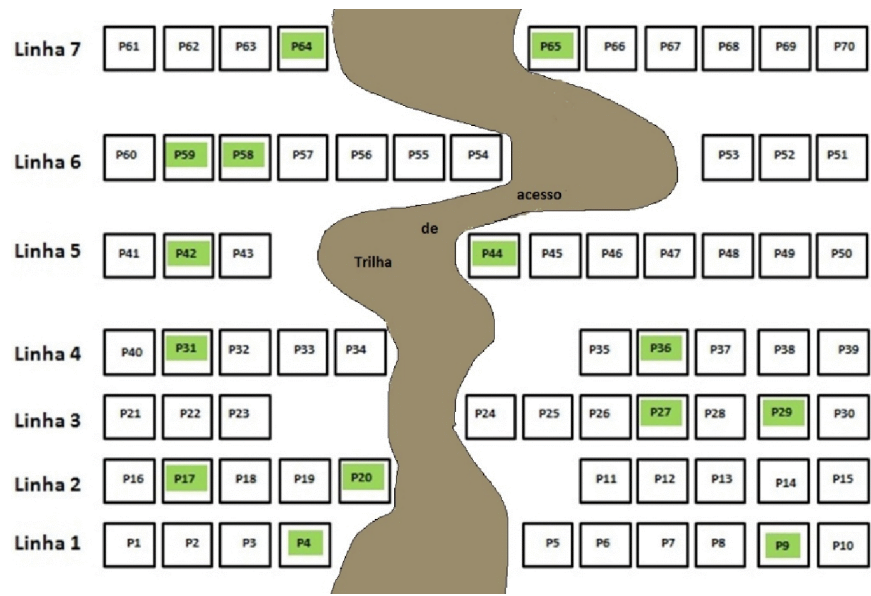

As faixas pintadas de verde identificam as parcelas que foram selecionadas para a coleta de serapilheira

Figura 2. Disposição das linhas (faixas) e parcelas (P1, $\mathrm{P} 2$, etc.) na área de estudos variando entre 3, 4, 5 ou 6 parcelas no lado direito e esquerdo da trilha no sentido do contínuo de vegetação do solo. Foram alocados dois coletores em cada faixa e realizados sorteios de duas parcelas por faixa para a escolha do local onde os coletores seriam alocados (para cada linha de 10 parcelas duas eram sorteadas) totalizando, assim, 14 coletores. Os coletores foram alocados no centro das parcelas escolhidas e sempre na posição horizontal evitando a diminuição da área de amostragem (Scoriza et al., 2012) (Figura 2).

A serapilheira interceptada pelos coletores foi coletada mensalmente durante o período de um ano, de fevereiro de 2011 a janeiro de 2012. Em cada coleta a serapilheira foi triada nas frações: folhas, flores, frutos e sementes, ramos com até $2 \mathrm{~cm}$ de diâmetro e restos (material fecal, insetos, plântulas, entre outros). Adotou-se este limite máximo de diâmetro para ramos visando padronizar a metodologia com outros estudos realizados em florestas tropicais (Martins \& Rodrigues, 1999).

Antes da triagem do material 50 embalagens de papel foram secadas a $100{ }^{\circ} \mathrm{C}$ em estufa a fim de obter seu peso seco, as quais foram pesadas, após este procedimento foi calculado o peso médio das embalagens. Desta forma, o presente trabalho teve uma precisão maior do peso das amostras de cada fração da serapilheira; depois da triagem as frações foram pesadas individualmente obtendo-se seu peso úmido; em seguida, as amostras foram secadas em estufa a $70{ }^{\circ} \mathrm{C}$ até obter peso constante.

Para o cálculo do valor total de serapilheira produzido, todas as frações coletadas em todos os meses foram somadas e obtidos valores em $\mathrm{g} \mathrm{m}^{-2}$. Com os valores obtidos das pesagens calculamos as médias mensais de deposição da serapilheira total e de suas frações expressando os valores em peso e em porcentagem de cada fração. Para a análise comparativa da produção de serapilheira entre as estações do ano, os meses foram agrupados em: verão (coletas de janeiro, fevereiro e março), outono (coletas de abril, maio e junho), inverno (coletas de julho, agosto e setembro) e primavera (coletas de outubro, novembro e dezembro). Para verificar diferenças significativas entre as frações estudadas foi utilizado o teste não paramétrico de Kruskal-Wallis, pois os dados não apresentavam uma distribuição normal, mesmo após a transformação. Como teste a posteriori utilizou-se o método de Dun. Para comparação entre as faixas de coleta e entre as estações do ano adotaram-se a análise multivariada Anova, um critério no programa Bioest 5.0 (Ayres et al., 2007) e, quando significativo, as médias foram comparadas pelo teste t de Student.

\section{Resultados e Discussão}

Os resultados da produção de serapilheira total e frações ao longo do ano de 2011 e 2012 podem ser observados na Tabela 1, cuja produção total média de serapilheira foi estimada $2809,02 \mathrm{~g} \mathrm{~m}^{-2}$, para as 7 faixas nas 14 parcelas nas quais foram alocados os coletores.

A maior produção de serapilheira ocorreu na primavera, com $31,69 \%$ do peso total $\left(890,07 \mathrm{~g} \mathrm{~m}^{-2}\right)$, seguida dos outono, com 24,88\% (698,99 $\left.\mathrm{g} \mathrm{m}^{-2}\right)$, inverno com $23,44 \%\left(658,44 \mathrm{~g} \mathrm{~m}^{-2}\right)$ e verão, com 19,99\% 561,52 $\mathrm{g} \mathrm{m}^{-2}$ ) (Tabela 1) embora a análise comparativa entre as estações do ano não tenha apresentado diferenças significativas $(\mathrm{F}=1.1655, \mathrm{gl}=8$ e $\mathrm{p}=0.3820)$. 
Tabela 1. Produção de serapilheira $\left(\mathrm{g} \mathrm{m}^{-2}\right)$ e contribuição percentual dos componentes da serapilheira correspondentes a cada mês e estações do período de $2011 / 2012$

\begin{tabular}{|c|c|c|c|c|c|}
\hline $\begin{array}{l}\text { Estações } \\
\text { do ano }\end{array}$ & Mês & $\begin{array}{l}\text { Total } \\
\left(\mathrm{g} \mathrm{m}^{-2}\right)\end{array}$ & $\begin{array}{l}\text { Proporção } \\
\text { mensal (\%) }\end{array}$ & $\begin{array}{c}\text { Total } \\
\text { das estações }\end{array}$ & $\begin{array}{c}\text { Proporção } \\
\text { da estaçâo (\%) }\end{array}$ \\
\hline \multirow{3}{*}{ Verão } & $\mathrm{jan} / 12$ & 235,83 & 8,40 & & \\
\hline & $\mathrm{fev} / 11$ & 174,63 & 6,22 & 561,52 & 19,99 \\
\hline & $\mathrm{mar} / 11$ & 151,06 & 5,38 & & \\
\hline \multirow{3}{*}{ Outono } & $\mathrm{abr} / 11$ & 366,13 & 13,03 & & \\
\hline & mai/11 & 104,04 & 3,70 & 698,99 & 24,88 \\
\hline & jun/11 & 228,82 & 8,15 & & \\
\hline \multirow{3}{*}{ Inverno } & $\mathrm{jul} / 11$ & 197,45 & 7,03 & & \\
\hline & ago/11 & 197,91 & 7,05 & 658,44 & 23,44 \\
\hline & set/11 & 263,08 & 9,37 & & \\
\hline \multirow{4}{*}{ Primavera } & out/11 & 331,13 & 11,79 & & \\
\hline & nov/11 & 261,43 & 9,31 & 890,07 & 31,69 \\
\hline & $\operatorname{dez} / 11$ & 297,51 & 10,59 & & \\
\hline & Total $\left(\mathrm{g} \mathrm{m}^{-2}\right)$ & 2809,02 & 100,00 & 2809,02 & 100,00 \\
\hline
\end{tabular}

Considerando os meses estudados dentro da estação primavera, a maior produção de serapilheira foi em outubro $\left(11,79 \%\right.$ - 331,13 $\mathrm{g} \mathrm{m}^{-2}$ de material coletado) e a menor em novembro, com 9,31\% $\left(261,43 \mathrm{~g} \mathrm{~m}^{-2}\right)$. O mês em que se obteve maior produção de serapilheira ao longo do ano, foi abril, com $13,03 \%\left(366,13 \mathrm{~g} \mathrm{~m}^{-2}\right)$ e a menor em maio, com $3,70 \%$ $\left(104,04 \mathrm{~g} \mathrm{~m}^{-2}\right)$.

Dentre as frações da serapilheira a que mais contribuiu para a produção total foi a fração folhas representando $73,86 \%$ do peso seco total $\left(2074,74 \mathrm{~g} \mathrm{~m}^{-2}\right)$, seguida pela fração ramos, com $18,89 \%$ da serapilheira total $\left(530,67 \mathrm{~g} \mathrm{~m}^{-2}\right)$, frutos $\mathrm{e}$ sementes 3,39\% $\left(95,18 \mathrm{~g} \mathrm{~m}^{-2}\right)$ restos 2,65\% $\left(74,48 \mathrm{~g} \mathrm{~m}^{-2}\right)$ e flores com 1,21\% (33,95 $\left.\mathrm{g} \mathrm{m}^{-2}\right)$ (Tabela 2). Encontramos diferença significativa entre a quantidade das frações coletadas na área de estudo $(\mathrm{H}=47.3399$, gl $=4$ e $\mathrm{p}<0.0001)$. As frações folhas e ramos apresentaram diferenças significativas com todas as outras frações estudadas.

Os maiores valores de produção da fração folha total ocorreram nos meses de outubro $\left(293,20 \mathrm{~g} \mathrm{~m}^{-2}\right)$ e dezembro $\left(246,18 \mathrm{~g} \mathrm{~m}^{-2}\right)$ e os menores valores em março $\left(93,75 \mathrm{~g} \mathrm{~m}^{-2}\right)$ e maio $\left(86,64 \mathrm{~g} \mathrm{~m}^{-2}\right)$.

Considerando as estações do ano para a fração folha, o pico de produção foi atingido na primavera. As folhas representam o compartimento mais importante na maioria dos estudos de produção de serapilheira em florestas tropicais (Vidal et al., 2007, Nunes \& Pinto, 2007; Caldeira et al., 2008; Godinho et al., 2013; Alonso et al., 2015). Esta fração depende principalmente das espécies, da estrutura do local e da idade das árvores (Caldeira et al., 2007; Vidal et al., 2007).

Martins \& Rodrigues (1999) verificaram que as altas taxas de deposição de folhas nos meses de setembro e outubro são consequência dos baixos índices pluviométricos observados nos meses anteriores (julho e agosto). Na estação seca o pico de deposição seria ocasionado pela grande quantidade de folhas liberadas pelas plantas, provocada como alternativa ao estresse hídrico (Dias \& Oliveira Filho, 1997). A elevada deposição de folhas em florestas também pode ser decorrência do rápido crescimento e da renovação foliar de espécies pioneiras canalizando os fotossimilados em um primeiro momento, à produção vegetativa (Martins \& Rodrigues, 1999; Werneck et al., 2001).

Dias \& Oliveira Filho (1997) sugerem que a ação mecânica realizada pelas chuvas e ventos pode promover queda das folhas. Segundo os autores, na estação seca o pico de deposição seria ocasionado pela grande quantidade de folhas liberadas pelas plantas, provocado como alternativa ao estresse hídrico. Em todas as áreas a fração foliar prevaleceu quantitativamente fato também observado por outros autores que encontraram valores entre 60 a 80\% (Pagano, 1989; Martins \& Rodrigues, 1999; Werneck et al., 2001; Vidal et al., 2007; Nunes \& Pinto, 2007).

A fração ramos apresentou máxima produção entre os meses de abril e junho, no outono, com 18,1\%. Entretanto, deve-se ressaltar que a participação desta fração na serapilheira total tem sido bastante variada em florestas com o menor valor de 4,86\% (Martins \& Rodrigues, 1999) e o maior de 32,6\% (Pagano, 1989).

As frações frutos e sementes alcançaram a máxima produção em junho e a mínima em agosto (outono e inverno, respectivamente) enquanto a fração restos alcançou a máxima produção em fevereiro e a mínima em março (verão).

Com menor participação na produção total de serapilheira e padrão de deposição bastante irregular durante o ano, a

Tabela 2. Produção de serapilheira $\left(\mathrm{g} \mathrm{m}^{-2}\right)$ e sua contribuição percentual dos componentes da serapilheira durante as 4 estações do período de 2011/2012

\begin{tabular}{|c|c|c|c|c|c|c|c|}
\hline \multirow[t]{2}{*}{ Estações do ano } & \multirow[t]{2}{*}{ Mês } & Folhas & Ramos & Flores & $\begin{array}{c}\text { Frutos e } \\
\text { sementes }\end{array}$ & Restos & Total \\
\hline & & \multicolumn{6}{|c|}{$\left(g^{-2}\right)$} \\
\hline \multirow{2}{*}{ Verão } & $\mathrm{fev} / 11$ & 113,54 & 40,78 & 1,42 & 10,14 & 8,75 & 174,63 \\
\hline & $\mathrm{mar} / 11$ & 93,75 & 49,99 & 0,27 & 4,07 & 2,98 & 151,06 \\
\hline \multirow{3}{*}{ Outono } & $\mathrm{abr} / 11$ & 228,59 & 123,19 & 0,61 & 7,30 & 6,44 & 366,13 \\
\hline & $\mathrm{mai} / 11$ & 86,64 & 9,24 & 0,37 & 2,34 & 5,45 & 104,04 \\
\hline & jun/11 & 126,02 & 71,61 & 1,20 & 23,70 & 6,29 & 228,82 \\
\hline \multirow{3}{*}{ Inverno } & $\mathrm{jul} / 11$ & 151,81 & 35,58 & 0,04 & 4,13 & 5,89 & 197,45 \\
\hline & $\mathrm{ago} / 11$ & 154,68 & 33,29 & 0,00 & 2,66 & 7,28 & 197,91 \\
\hline & set/11 & 233,28 & 16,97 & 5,90 & 3,67 & 3,26 & 263,08 \\
\hline \multirow{3}{*}{ Primavera } & out $/ 11$ & 293,20 & 25,00 & 1,34 & 4,03 & 7,56 & 331,13 \\
\hline & nov $/ 11$ & 211,97 & 32,53 & 6,60 & 4,20 & 6,13 & 261,43 \\
\hline & $\mathrm{dez} / 11$ & 246,18 & 31,60 & 4,48 & 8,84 & 6,41 & 297,51 \\
\hline \multirow[t]{3}{*}{ Verão } & $\mathrm{jan} / 12$ & 135,08 & 60,89 & 11,72 & 20,10 & 8,04 & 235,83 \\
\hline & Total $\left(\mathrm{g} \mathrm{m}^{-2}\right)$ & 2074,74 & 530,67 & 33,95 & 95,18 & 74,48 & 2809,02 \\
\hline & Proporção (\%) & 73,86 & 18,89 & 1,21 & 3,39 & 2,65 & 100 \\
\hline
\end{tabular}


Tabela 3. Produção de serapilheira $\left(\mathrm{g} \mathrm{m}^{-2}\right)$ e sua contribuição percentual dos componentes da serapilheira correspondentes a cada faixa do período de 2011/2012

\begin{tabular}{|c|c|c|c|c|c|c|c|c|}
\hline Meses & FX1 & FX 2 & FX 3 & $\overline{F X 4}$ & FX 5 & FX 6 & FX 7 & Total \\
\hline Jan/12 & 34,09 & 34,21 & 54,22 & 20,06 & 40,05 & 27,00 & 26,20 & 235,83 \\
\hline $\mathrm{Fev} / 11$ & 34,35 & 17,62 & 23,32 & 15,85 & 36,12 & 23,00 & 24,37 & 174,63 \\
\hline $\mathrm{Mar} / 11$ & 17,77 & 13,76 & 29,13 & 15,43 & 39,31 & 18,08 & 17,58 & 151,06 \\
\hline $\mathrm{Abr} / 11$ & 60,95 & 33,11 & 38,51 & 75,13 & 71,59 & 55,66 & 31,18 & 366,13 \\
\hline $\mathrm{Mai} / 11$ & 20,96 & 8,66 & 11,03 & 17,10 & 21,25 & 13,87 & 11,17 & 104,04 \\
\hline Jun/11 & 43,15 & 19,01 & 23,00 & 41,48 & 49,59 & 43,03 & 9,56 & 228,82 \\
\hline $\mathrm{Jul} / 11$ & 39,54 & 32,97 & 18,67 & 24,72 & 31,61 & 34,99 & 14,95 & 197,45 \\
\hline Ago/11 & 43,39 & 24,96 & 17,59 & 24,19 & 33,92 & 30,61 & 23,25 & 197,91 \\
\hline Set/11 & 47,19 & 40,28 & 26,78 & 37,20 & 44,46 & 33,28 & 33,89 & 263,08 \\
\hline Out/11 & 58,79 & 52,02 & 33,68 & 37,03 & 49,04 & 45,85 & 54,72 & 331,13 \\
\hline Nov/11 & 43,88 & 37,37 & 38,02 & 22,29 & 38,08 & 27,11 & 54,68 & 261,43 \\
\hline Dez/11 & 57,19 & 39,42 & 46,29 & 30,02 & 45,21 & 33,61 & 45,77 & 297,51 \\
\hline Total & 501,25 & 353,39 & 360,24 & 360,50 & 500,23 & 386,09 & 347,32 & 2809,02 \\
\hline Proporção (\%) & 17,84 & 12,58 & 12,82 & 12,83 & 17,81 & 13,74 & 12,36 & 100 \\
\hline
\end{tabular}

FX = Faixa

fração flores apresentou picos de produção em janeiro (verão), com menor produção da fração em outono. A produção das frações, flores, frutos e sementes está diretamente relacionada à diversidade de espécies presentes na área de estudo e à sua fenologia. Os valores de produção desse material em um mesmo tipo de floresta podem variar de acordo com a área estudada de vez que estão na dependência das condições abióticas locais, da composição florística, da demografia de cada espécie e da estrutura da vegetação (Diniz \& Pagano, 1997; Pivello et al., 2006).

Não foi encontrada diferença significativa entre a serapilheira depositada nas faixas, ao longo do gradiente mina - continum florestal $(\mathrm{F}=2.0949, \mathrm{gl}=6 \mathrm{e} \mathrm{p}=0.0628$ ) (Tabela 03). A faixa 1 apresentou a maior produção de serapilheira, $17,84 \%\left(501,25 \mathrm{~g} \mathrm{~m}^{-2}\right)$, seguida pela faixa $5 \mathrm{com} 17,81 \%(500,23$ $\left.\mathrm{g} \mathrm{m}^{-2}\right)$, faixa 6 com $13,74 \%\left(386,09 \mathrm{~g} \mathrm{~m}^{-2}\right)$, faixa 4 com $12,83 \%$ $\left(360,50 \mathrm{~g} \mathrm{~m}^{-2}\right)$, faixa $3 \mathrm{com} 12,82 \%\left(360,24 \mathrm{~g} \mathrm{~m}^{-2}\right)$, faixa $2 \mathrm{com}$ $12,58 \%\left(353,39 \mathrm{~g} \mathrm{~m}^{-2}\right)$ e, com menor deposição de serapilheira, a faixa 7 apresentou $12,36 \%$ do total coletado $\left(347,32 \mathrm{~g} \mathrm{~m}^{-2}\right)$.

Os valores alcançados na produção de serapilheira ao longo das 7 faixas do contínuo apresentaram valores similares. As faixas próximo à cava de mineração se encontram sobre solo com presença de rochas e relevo acidentado o que, provavelmente, pode estar interferindo na quantidade de espécies arbóreas (CCRG, 2012) mas não na produção de serapilheira visto que a faixa 1 obteve maior produção de serapilheira. Na vegetação herbácea da Mina Limeira observou-se que as faixas nas quais ocorreu maior intervenção humana, houve maior número de indivíduos e também a presença de espécies exóticas (possivelmente introduzidas na área) como, por exemplo, Heliconia sp. (Musaceae) (CCRG, 2012). Os coletores alocados próximo a essas áreas não sofreram interferência na produção de serapilheira em relação aos outros coletores ao longo do contínuo de vegetação.

Conforme se dá o distanciamento da cava de mineração (faixas a 40, 80 e $160 \mathrm{~m}$ ) encontraram maior riqueza de espécies sendo que as faixas a 320 e $640 \mathrm{~m}$ apresentaram menor riqueza (CCRG, 2012). Em referência à produção de serapilheira; foi nas faixas a $10 \mathrm{~m}$ e $80 \mathrm{~m}$ que obtivemos maior produção e menor nas faixas $10 \mathrm{~m}$ e $640 \mathrm{~m}$. Vários fatores bióticos e abióticos afetam a produção de serapilheira, como tipo de vegetação, altitude, latitude, precipitação, temperatura, regimes de luminosidade, deciduidade da vegetação, estádio sucessional, disponibilidade hídrica e características do solo (Figueiredo Filho et al., 2003). Demonstra-se, com os dados obtidos, que a cava da mineração não é um fator que pode afetar a produção de serapilheira.

\section{Conclusões}

1. A produção total de serapilheira alcançou um valor máximo na primavera e a menor no verão, durante o período de estudo; entretanto, as variações encontradas não foram estatisticamente significativas.

2. A fração folhas foi a mais representativa, com $73,86 \%$ do peso seco total do material depositado nos coletores no período de um ano.

3. Não houve diferença significativa na produção de serapilheira ao longo das faixas estudadas.

4. A cava da mina não está prejudicando o ciclo natural de produção de serapilheira, um dos serviços ecossistêmicos fundamentais para a manutenção dos recursos naturais, pelo menos até a presente data.

\section{Literatura Citada}

Aidar, M. P. M.; Godoy, J. R. L.; Bergmann, J.; Joly, C. A. Atlantic forest calcareous soil, Parque Estadual Turístico do Alto Ribeira-PETAR, SP. Revista Brasileira de Botânica, v.24, p.455-469, 2001. http:// dx.doi.org/10.1590/S0100-84042001000400012

Alonso, J. M.; Leles, P. S. S.; Ferreira, L. N.; Oliveira, N. S. A. Aporte de serapilheira em plantio de recomposição florestal em diferentes espaçamentos. Ciência Florestal, v.25, p.1-11, 2015. http://dx.doi.org/10.5902/1980509817439

Ayres, M.; Ayres Júnior, M.; Ayres. D. L. Santos. A. A. S. BioEstat Aplicação estatísticas nas áreas das ciências bio-médicas. Belém: Sociedade Civil Mamirauá; MCT; Impressa Oficial do Estado do Pará, 2007. 380p.

Bacci, D. L. C; Landim, P. M. B.; Eston, S. M. Aspectos e impactos ambientais de pedreira em área urbana. Revista Escola de Minas, v.59, p.47-54, 2006. http://dx.doi.org/10.1590/S037044672006000100007

Baider, C. O banco de sementes e de plântulas na sucessão da Mata Atlântica. São Paulo: Universidade de São Paulo, 1994. 137p. Dissertação Mestrado 
Caldeira, M. V. W.; Marques, R.; Soares, R. V.; Balbinot, R. Quantificação de serapilheira e de nutrientes - Floresta Ombrófila Mista Montana - Paraná. Revista Acadêmica, v.5, p.101-116, 2007.

Caldeira, M. V. W.; Vitorino, M. D.; Schaadt, S. S.; Moraes, E.; Balbinot, R. Quantificação de serapilheira e de nutrientes em uma Floresta Ombrófila Densa. Semina: Ciências Agrárias, v.29, p.53-68, 2008. http://dx.doi.org/10.5433/1679-0359.2008v29n1p53

Câmara, I. G.; Coimbra Filho, A. F. Proposta para uma política de conservação ambiental para o estado do Rio de Janeiro. In: Bergalho, H. G.; Rocha, C. F. D.; Alves, M. A. S.; Sluys, M. van. A fauna ameaçada de extinção do estado do Rio de Janeiro. Rio de Janeiro: Universidade do Estado do Rio de Janeiro, 2000, p.137-143.

CCRG - Companhia de Cimento Ribeirão Grande. Ampliação da Mina Limeira: Estudo de impacto ambiental. São Paulo: CCRG, v.2. 2003. 267p.

CCRG - Companhia de Cimento Ribeirão Grande. Monitoramento e avaliação da vegetação nas áreas de influência direta da Mina Limeira (Continuum Florestal e Depósito Estéril Barro Branco). São Paulo: Companhia de Cimento Ribeirão Grande. 2012. 238p. Relatório de Pesquisa

Dias, H. C. T.; Oliveira Filho, A. T. Variação temporal e espacial da produção de serapilheira em uma área de Floresta Estacional Semidecídual Montana em Lavras, MG. Revista Árvore, v.21, p.11-26, 1997.

Diniz, S.; Pagano, S. N. Dinâmica de folheado em floresta mesófila semidecídua no município de Araras, SP. Revista do Instituto Florestal, v.9, p.27-36, 1997.

Figueiredo Filho, A.; Moraes, G. F.; Schaaf, L. B.; Figueiredo, D. J. de. Avaliação Estacional da Deposição de Serapilheira em uma Floresta Ombrófila Mista Localizada no Sul do Paraná. Ciência Florestal, v.13, p.11-18, 2003.

Leal, C. G.; Câmara, I. G. Mata Atlântica biodiversidade, ameaças e perspectivas. Fundação SOS Mata Atlântica - Belo Horizonte: Conservação Internacional, 2005. 472p.

Godinho, T. de O.; Caldeira, M. V. W.; Caliman, J.P; Prezotti, L.C.; Watzlawick, L.F.; Azevedo, H.C.A. de; Rocha, J.H.T. Biomassa, macronutrientes e carbono Orgânico na serapilheira depositada em trecho de floresta Estacional Semidecidual Submontana, ES. Scientia Forestalis, v.41, p.131-144, 2013.

IBGE - Instituto Brasileiro de Geografia e Estatística. Manual técnico da vegetação brasileira. Rio de Janeiro: IBGE, 2.ed., 2012. 275p.

Jakovac, A. C. C. O uso do banco de sementes florestal contido no topsoil como estratégia de recuperação de áreas degradadas. Campinas: Instituto de Biologia da UNICAMP, 2007. 190p. Dissertação Mestrado
Klumpp, A. Utilização de bioindicadores de poluição em condições temperadas e tropicais. In: Maia, N. B.; Martos, H. L.; Barrella, W. (ed.). Indicadores ambientais: Conceitos e aplicações. São Paulo: EDUC/COMPED/INEP, 2001. p.77-94.

Machado, M. R.; Piña Rodrigues, F. C. M.; Pereira, M. G. Produção de serapilheira como bioindicador de recuperação em plantio adensado de revegetação. Revista Árvore, v.32, p.143-151, 2008. http://dx.doi.org/10.1590/S0100-67622008000100016

Martins, S. V.; Rodrigues, R. R. Produção de serrapilheira em clareiras de uma floresta estacional semidecidual no município de Campinas, SP. Revista Brasileira de Botânica, v.22, p.405- 412, 1999. http://dx.doi.org/10.1590/S0100-84041999000300009

Mittermeier, R. A. Fonseca, G. A. B. Rylands, A. B. \& Brandon, K. Uma breve história da conservação da biodiversidade no Brasil. Megadiversidade, v.1, p.14-21, 2005.

Nunes, F. P.; Pinto, M. T. C. Produção de serapilheira em mata ciliar nativa e reflorestada no alto São Francisco, Minas Gerais. Biota Neotropica, v.7, p.097-102, 2007.

Pagano, S. N. Produção de folheado em uma mata semidecídua no município de Rio Claro, SP. Revista Brasileira de Biologia, v.49, p.633-639, 1989.

Pivello, V. R.; Petenon, D.; Jesus, F. M. de; Meirelles, S. T.; Vidal, M. M.; Alonso, R. de A. S.; Franco, G. A. D. C; Metzger, J. P. Chuva de sementes em fragmentos de Floresta Atlântica (São Paulo, SP, Brasil), sob diferentes situações de conectividade, estrutura florestal e proximidade da borda. Acta Botânica Brasílica, v.20, p.845-859, 2006. http://dx.doi.org/10.1590/S0102-33062006000400010

Schumacher, M. V.; Trüby, P.; Marafiga, J. M.; Viera, M.; Szymczak, D. A. Espécies predominantes na deposição de serapilheira em fragmento de floresta estacional decidual no Rio Grande do Sul. Ciência Florestal, v.21, p.479-486, 2011. http://dx.doi.org/10.5902/198050983805

Scoriza, R. N.; Pereira, M. G.; Pereira, G. H. A.; Machado, D. L.; Silva, E. R. Métodos para coleta e análise de serrapilheira aplicados à ciclagem de nutrientes. Floresta e Ambiente, v.2, p.1-18, 2012.

Spain, A. V. Litterfall and the standing crop of litter in three tropical Australian rainforests. Journal of Ecology, v.72, p.947-961, 1984. http://dx.doi.org/10.2307/2259543

Vidal, M. M.; Pivello, V. R; Meirelles, S. T.; Metzger, J. P. Produção de serapilheira em floresta Atlântica secundária numa paisagem fragmentada (Ibiúna, SP): Importância da borda e tamanho dos fragmentos. Revista Brasileia de Botânica, v.30, p.521-532, 2007. http://dx.doi.org/10.1590/s0100-84042007000300016

Werneck, M. S., Pedralli, G.; Gieseke, L. F. Produção de serrapilheira em três trechos de uma floresta semidecidual com diferentes graus de perturbação na Estação Ecológica de Tripuí, Ouro Preto, MG. Revista Brasileira de Botânica, v.24, p.195-198, 2001. http://dx.doi. org/10.1590/S0100-84042001000200009 